\title{
Editorial
}

\section{O lugar do qualitativo na pesquisa em Enfermagem}

De Antônio Candido sobre a literatura, parafraseada para a pesquisa em Enfermagem "entendo aqui por humanizaçâa [...] o processo que confirma no homem aqueles traços que reputamos essenciais, como o exercicio da reflexão, a aquisição do saber, a boa disposiçāo para com o próximo, o a finamento das emoçóes, a capacidade de penetrar nos problemas da vida, o senso da beleza, a percep̧̧áo da complexidade do mundo e dos seres, o cultivo do humor. A literatura [a pesquisa qualitativa] [deve desenvolver] desenvolve em nós a quota de humanidade na medida em que nos torna mais compreensivos e abertos para a natureza, a sociedade, semelhante".(1)

$\mathrm{N}$ o mundo atual da saúde e da Enfermagem, especialmente relativo à pesquisa, divulgação e avaliação da produção, o quantitativo é completamente aceito como sinônimo de cientificidade. Já fomos, desde a graduação, direcionadas a acreditar que esta é a melhor, senão a única forma de se aproximar da realidade no sentido de pesquisar ou divulgar ou avaliar.

Neste Editorial, que desde já agradeço à Editora Chefe pelo honroso convite, pretendo mostrar, muito brevemente, que o quantitativo não sobreviveria se não tivesse o qualitativo como complemento ou como nuclear da produção científica, especialmente de pesquisas cujo foco é o ser humano, quer indivíduo, quer coletivo. Não vou fazer defesa do quantitativo, aceito que é de extrema importância a quantificação de partes dos fenômenos que, fracionados, apresentam-se com "dotes" bem mais universais e que podem dar respostas universais ou gerais. Em defesa do qualitativo, escolhi alguns aspectos que merecem ser pensados: a importância da qualidade; a possiblidade ou o imperativo para fenômenos complexos; e por fim, o qualitativo com poder de alavancar as pesquisas, a divulgação e a avaliação da produção científica.

Sempre me inspiro na Maria Cecília de Souza Minayo para falar de qualidade. Em seu livro, em co-autoria com Costa "Tecnicas que fazem uso da Palavra, do Olhar e da empatia: pesquisa qualitativa em açáo", os autores nos ensinam que as pesquisas qualitativas têm como matéria prima um conjunto de substantivos cujos sentidos se complementam: experiência, vivência, senso comum e ação. E o movimento que informa qualquer abordagem ou análise [...] se baseia em três verbos: compreender, interpretar e dialetizar." ${ }^{(2)}$

O livro "Investigação Qualitativa: Inovação, Dilemas e Desafios Volume 2 " não pode faltar aos que pensam seriamente na qualidade das pesquisas. ${ }^{(3)}$ 
Para Egry e Fonseca ${ }^{(4)}$ a qualidade sinaliza a intensidade que é oposta à extensividade, a primeira apontando para o melhor e a segunda ao maior e busca enxergar as dimensóes dos fenômenos que: apresentam marcas da profundidade, como o amor; reagem à rotina, buscando renovar-se, como a felicidade; primam pelo compromisso, tal como o engajamento político, ou a militância; indicam a plenitude da realização humana, como a santidade; valorizam a participação humana, como a democracia, a cidadania; apontam para as dimensôes valorativas do ser humano, como a dedicação, a ética, a abnegação, o envolvimento, a prestatividade, a solidariedade etc.

Uma rápida olhada nas publicaçóes indexadas internacionais sobre o tema, mostra que houve uma incorporação crescente de artigos dentro do amplo espectro das metodologias qualitativas. Se por um lado houve expansão, por outro houve certa banalização dos estudos referentes ao método. A grande diferença e importância da metodologia qualitativa ao tentar se aproximar do objeto de estudo é o seu quadro teórico, ou fundamentos do método. Se isto não fica claro no estudo, ele é apenas um recorte diminutivo e pontual de um estudo que poderia ser quantitativo, mas que faltou "quantidades" para demonstração.

Ao propiciar o aprofundamento da visão da realidade, buscando a essência dos fenômenos, a pesquisa qualitativa pode ser a chave para a produçáo de um conhecimento crítico, emancipador e profundamente comprometido com a transformação social.

Entretanto, o estudo de Thorne et al. ${ }^{(5)}$ contesta o uso extensivo de abordagens convencionais ao desenho alinhados às pesquisas das ciências sociais. Para estas autoras ao invés do alinhamento direto, deveria se apoiar na epistemologia da Enfermagem, como um passo altamente profícuo para recortar o problema de estudo. Concordamos com as autoras de que apesar da Enfermagem ser caracterizada por um núcleo filosófico coerente que unifica através de práticas das mais diversas em termos de configuração e contextos, essa prórpia complexidade e natureza da Enfermgem tornam excepcionalmente difícil a tarefa de definir os marcos.

Considero extremamente interessante e profícuo o que as autoras advogam, diante da premissa de que uma questão de pesquisa em enfermagem nunca é livre de contexto, mas surge "com base na reflexão crítica, informados por uma consciência das limitaçóes do conhecimento atual para a prática da profissão. [...] assume uma orientação inerentemente práxica, no sentido de que a dialética entre o conhecimento e a ação sobre a qual sua base determinará, em última análise, dá utilidade e valor", (tradução livre). ${ }^{(5,6)}$

A conclusão que podemos chegar e que outras áreas do conhecimento já chegaram antes do que nós é que para compreender a realidade objetiva no sentido de intervir - e esta é a missão cuidativa da Enfermagem - o caminho mais fértil é a aliança entre o quantitativo e o qualitativo. Melhor dizendo, não há maneira de investigar senão pela aliança quantitativo-qualitativo os projetos de pesquisa, ou de intervenção que abordarem fenômenos complexos, tais como acessibilidade ao cuidado e terapêutica, o enfrentamento da violência doméstica, a expansão inusitada de doenças que pareciam que 
ficaram na história, o desenvolvimento de novas maneiras de olhar epidemiológico crítico no território ou nas populações deslocadas forçosamente (migrantes).

Sabemos que a ciência está longe de ser certa e definitiva, mesmo com todo o rigor científico do método, pois deriva de movimentos contínuos de superação dialética dos conhecimentos anteriores.

A qualidade nas pesquisas qualitativas depende da adoção de um marco teórico filosófico que possa abranger fenômenos complexos e não redutíveis a descrições puramente numéricas; do objeto a ser estudado e do quanto ele comporta uma aproximaçáo qualitativa; da metodologia e do caminho metodológico, que devem ser escolhidos de forma a iluminar o fenômeno em totalidades-parte e ao final reconstruí-lo em síntese das contradiçôes a serem superadas; da rigorosidade e da transparência do quadro teórico e do caminho metodológico, das categorias de análise e das técnicas de análise dos dados; da análise aprofundada dos achados mediante intertexto com resultados de outras pesquisas, amplas e atuais; da síntese que contemple as dimensôes do singular, do particular e do geral; da ética na condução da pesquisa e na devolução e na divulgação dos resultados.

Finalmente, é importante reconhecer que a qualidade na pesquisa qualitativa está na dependência da produção de um conhecimento socialmente significativo para as pessoas e o conjunto da sociedade.

Profa Dra Emiko Yoshikawa Egy (https://orcid.org/0000-0003-0974-0315) Professora Titular aposentada da Escola de Enfermagem da Universidade de São Paulo. Professor Visitante da Escola Paulista de Enfermagem da Universidade Federal de São Paulo (2019-2020). Editora Chefe da Revista da Escola de Enfermagem da Universidade de São Paulo. Pesquisadora Produtividade Sênior Conselho Nacional de Desenvolvimento Científico e Tecnológico-CNPq.

Como citar:

Egy EY. O lugar do qualitativo na pesquisa em Enfermagem. Acta Paul Enferm. 2020;33:e-EDT20200002

DOI:http://dx.doi.org/10.37689/acta-ape/2020EDT0002

\section{Referências}

1. Candido A. Direitos Humanos e literatura. In: Fester ACR, organizador. Direitos humanos e ... . São Paulo: Brasiliense; 1989. 
2. Minayo MC, Costa AP. Técnicas que fazem uso da palavra, do olhar e da empatia: pesquisa qualitativa em ação. Aveiro: Ludomedia; 2019. 64 p.

3. Costa AP, Coutinho C, Sánchez C, Souza DN, Egry EY, Souza FN, et al. Investigação qualitativa: inovação, dilemas e desafios. Souza FN de, Souza DN de, Costa AP, organizadores. Aveiro - Portugal: Ludomedia; 2014. vol. 1, 152 p.

4. Egry EY, Fonseca RM. Acerca da qualidade nas pesquisas qualitativas em Enfermagem. In: Costa AP, Neri de Souza F, Neri de Souza D, organizadores. Investigação qualitativa: inovação, dilemas e desafios. Aveiro: Ludomedia; 2014. p. 75-102.

5. Thorne S, Stephens J, Truant T. Building qualitative study design using nursing's disciplinary epistemology. J Adv Nurs. 2016;72(2):451-60.

6. Reed PG. The practice turn in nursing epistemology. Nurs Sci Q. 2006;19(1):36-8. 